\title{
Facile synthesis of mesoporous carbon material from treated kitchen waste for energy applications
}

\author{
Prabhsharan Kaur ${ }^{1} \cdot$ Subhashini Singh ${ }^{2} \cdot$ Gaurav Verma $^{1,3}[$
}

Received: 13 November 2017 / Accepted: 28 March 2018 / Published online: 31 March 2018

(c) The Author(s) 2018

\begin{abstract}
Biomass is abundant, easily available, and environmentally benign source of $\mathrm{C}$ which can be converted to scientifically useful materials by appropriate processing. This work is our attempt to convert the treated kitchen waste and chicken manure into valuable mesoporous carbons, and to check its suitability for energy applications. The samples have been prepared using hightemperature carbonization method, and the results are investigated for physical, chemical, and preliminary electrochemical studies. The synthesized porous carbons have mesoporous size distributions $(10.29 \mathrm{~nm})$ along with high-doped $\mathrm{N}$ content (9.2 at. \%). An increase in the disordered porous structure and, hence, the number of active sites have been observed under field-emission scanning electron microscopy. In the electrochemical studies, a positive shift of $-0.104 \mathrm{~V}$ has been observed in the oxygen reduction onset potential of the kitchen waste and chicken manure-based mesoporous carbons as compared to the control sample. Interestingly, the electrocatalytic performance is even comparable to the commercial Pt/C-based electrocatalyst. These studies indicate the suitability of the designed electrocatalyst for clean energy devices. Our approach is also an effective way to dispose-off the kitchen waste by modifying it using poultry faeces, which is a remedy to manage large-scale organic waste.
\end{abstract}

Keywords Biomass $\cdot$ Mesoporous carbons $\cdot$ Kitchen waste $\cdot$ Sustainability $\cdot N$-doping $\cdot$ Poultry faeces

\section{Introduction}

A continual use of fossil fuel reserves is leading us towards an alarming situation, where we have to devise some alternative means of energy generation. Hence, there are persistent efforts to replace present-day fuel resources with more economic, environment-friendly, and advanced alternative fuels [1]. A rapid industrial growth and increasing world population are adding on to this pressure with each passing day. In this scenario, most viable and practical approach is

Gaurav Verma

gauravverma@pu.ac.in; gauravvermas@gmail.com

1 Dr Shanti Swarup Bhatnagar University Institute of Chemical Engineering \& Technology (Formerly Department of Chemical Engineering \& Technology), Panjab University, Sector 14, Chandigarh 160014, India

2 Department of Chemical Engineering, Sant Longowal Institute of Engineering and Technology (SLIET), Longowal, Sangrur, Punjab 148106, India

3 Centre for Nanoscience and Nanotechnology, UIEAST, Panjab University, Chandigarh 160014, India to look back at technologies which were in use before the advent of using non-renewable sources. Biomass is in use for various means of energy generation since the beginning of mankind. The materials such as firewood, crop residues, manure, or charcoal used in a traditional way have been the main energy source for most of the human history and still play relevant roles. It is the biological matter which includes all living matter on the earth. Biomass-based materials are indeed advantageous for the three most important reasons: it is renewable source, hence an everlasting solution for the developments in the future as compared to conventional fossil fuels; it is an environment-friendly source of energy as it releases $\mathrm{CO}_{2}$ and sulphur contents in fewer amounts; and it is more economic and financially viable as compared to the costlier fossil fuels [2].

Biomass accounts for $\sim 10 \%$ of the world energy consumption [3]. It mainly consists of cellulose $\left(\mathrm{C}_{6} \mathrm{H}_{10} \mathrm{O}_{5}\right)_{\mathrm{x}}$, hemicelluloses $\left(\mathrm{C}_{5} \mathrm{H}_{8} \mathrm{O}_{4}\right)_{\mathrm{m}}$, lignin $\left[\mathrm{C}_{9} \mathrm{H}_{10} \mathrm{O}_{3}\left(\mathrm{COH}_{3}\right)_{0.9-1.7}\right]_{\mathrm{n}}$, proteins, fats, sugars, water, ash content, etc. Cellulose is the main constituent of biomass; it is 35-50\% of biomass by weight. Lignin is $15-20 \%$ and hemicelluloses are about $20-35 \%$ of biomass weight, while the remaining $15-20 \%$ 
is fats, proteins, ash content, and small extractives [4]. In general, biomass is classified into six sub-groups: wood and woody biomass, aquatic biomass, contaminated and industrial biomass waste, herbaceous and agricultural biomass, animal and human biomass waste, and biomass mixtures from all these varieties [5]. The individual characteristics of each category of biomass depend upon their physical properties, ultimate analysis, and proximate analysis. The properties change in every natural material with time, age, and growth environment [6].

Besides using biomass-based materials as alternative fuels to the conventional fuels, significant efforts are going on to utilize biomass and waste materials for several energybased applications [7-9]. One major concern is the commercialization of clean energy devices such as Fuel cell (FC). A major hurdle in FC operation is the slow kinetics of oxygen reduction reaction (ORR) occurring at the cathode. An electrocatalyst is required to speed it up, and conventionally, $\mathrm{Pt} / \mathrm{C}$ is the material of choice for this. However, it is a costlier metal, and another major issue associated with it is the $\mathrm{CO}$ poisoning which degrades the operational stability of an FC [10]. A recent breakthrough in this direction is the use of porous carbon material (PCM) (synthesized using biomass materials) based cathode electrocatalysts to fasten the rate of ORR [11, 12]. Sun et al. [13] synthesized high surface area $\left(1177.76 \mathrm{~m}^{2} \mathrm{~g}^{-1}\right)$ PCM by carbonizing waste cornstalks at $1000{ }^{\circ} \mathrm{C}$. It was observed that temperature and heteroatom dopants such as $\mathrm{N}$ greatly influence the number of active sites and operational stability of the PCM. N-doping in PCM is special as it induces charge delocalization and promotes the cleavage of $\mathrm{O}-\mathrm{O}$ bonds to speed up the oxygen reduction process at the cathode of an FC. Pomelo peels were utilized to synthesize $\mathrm{N}$-doped nanoporous carbons with a surface area up to $1444.9 \mathrm{~m}^{2} \mathrm{~g}^{-1}$ and high-doped graphitic-N content [14, 15]. Zhang et al. [16] carbonized bamboo leaves at high temperature to design an effective electrocatalyst with higher methanol tolerance, operational stability, and CO poisoning resistance as compared to $\mathrm{Pt} / \mathrm{C}$. Protein-rich fish scales were converted to porous nanocarbons via two-step pyrolysis method following some chemical activation and acidic treatment methods [17]. It is reported that the doped heteroatoms, high surface area, and inner architecture of the porous carbons contributed towards it. Similarly, coffee bean waste [18], napkin paper [19], and soya [20] have been used as precursors to synthesize PCM with 1213,1839 , and $1072 \mathrm{~m}^{2} \mathrm{~g}^{-1}$ surface area, respectively.

The potential of waste fruit peels has also been suggested for various applications [21-26]. Pathak et al. [21] suggested the use of fruit peels (banana, citrus, orange, and jackfruit) for the extraction of some valuable compounds (such as phenolic antioxidants, carboxylic acid, enzymes, and bioactive chemicals), energy generation (bio-methane, bio-hydrogen, gasification, bio-oil, bio-ethanol, etc.), bio-adsorbents, and bio-fertilizers. Fruit peels contain 3\% phenolic compounds, 0.8-9\% lignin, 9-59\% cellulose, and 8-17\% hemicelluloses, along with high $\mathrm{C}$ and $\mathrm{H}$ contents. All these compositions make them suitable for the above-said application areas. However, to the best of our knowledge, no such report on the electrochemical potential of fruit peels or other kitchen waste exists. This sets up the motivation to undertake the current research work. To utilize the solid waste of our institute, we have utilized the hostel (dormitories) and university eateries kitchen waste and processed it scientifically to synthesize valuable PCM which could be used for electrochemical as well as other applications. An organic manure was prepared, by decomposing kitchen waste into soil, and further poultry faeces were also added to it to make it nutrient rich ( $\mathrm{N}$ in specific). A high-temperature treatment of this organic manure gives rise to PCM. Our approach is unique and innovative to discard kitchen wastage (fruits and vegetable peels, tea, eggs, etc.) and get something very valuable which could have the potential to replace costlier $\mathrm{Pt} / \mathrm{C}$ as an electrocatalyst in an FC. The results have been characterized via FESEM, BET, EDX, XRD, FTIR, CV, and LSV studies.

\section{Experimental section}

\section{Synthesis of organic manure and PCM}

Kitchen waste was collected from different sources of our institute campus, like hostel mess, and university eateries. This ensures a very wide and heterogeneous composition for biomass sources, a necessity for procuring a good mix of elements. In a typical synthetic process, the kitchen waste collected from all sources and was segregated into different vegetable and fruit peels. A list of the collected kitchen waste and their elemental compositions are given in Table 1. The peels were separately ground in a home grinder. The ground paste of various peels was then mixed together in equal proportions to make a consistent mixture of kitchen waste paste of a $500 \mathrm{ml}$ volume. The mixture was then divided into three equal parts. Two pits were dug at different locations within the university premises. All the pits were filled with kitchen waste paste and covered. To enrich the paste with $\mathrm{N}$, poultry faeces were further added to one of the two pits [27]. This step was performed to check the effects of increased $\mathrm{N}$ content on the synthesized porous carbons. Regular intermixing was done at the equal time intervals for proper decomposition activity of anaerobic microbes. Higher humidity and moderate temperature favour fast decomposition of organic manure which was already prevailing during that weather (temperature ranged from 23 to $35^{\circ} \mathrm{C}$ and humidity ranged from 60 to $90 \%$ ). Under these weather conditions, the kitchen waste was completely converted into the 
Table 1 Elemental composition of different organic waste procured from kitchen

\begin{tabular}{|c|c|c|c|c|}
\hline \multirow[t]{2}{*}{ S. no. } & \multirow[t]{2}{*}{ Name of organic waste } & \multicolumn{3}{|l|}{ Elemental composition } \\
\hline & & Macronutrients & Micronutrients & Other elements \\
\hline \multicolumn{5}{|c|}{ Vegetable peels } \\
\hline a. & Cabbage & $\begin{array}{l}\text { Higher protein content, } \mathrm{N}, \mathrm{P} \\
\mathrm{Ca}, \mathrm{Mg}, \mathrm{Na}, \mathrm{K}\end{array}$ & $\mathrm{Co}, \mathrm{Cu}, \mathrm{Fe}, \mathrm{Mn}, \mathrm{Zn}$ & $\mathrm{Al}, \mathrm{As}, \mathrm{Ba}, \mathrm{Pb}, \mathrm{Li}, \mathrm{Ni}$ etc. \\
\hline b. & Ladyfinger & $\mathrm{K}, \mathrm{Ca}, \mathrm{Mg}$, and $\mathrm{Na}$ & $\mathrm{Fe}, \mathrm{Cu}, \mathrm{Zn}, \mathrm{Mn}$, and & \\
\hline c. & Onion & $\mathrm{N}, \mathrm{P}$, and $\mathrm{K}$ & $\mathrm{Ca}, \mathrm{Mg}, \mathrm{Mn}$, and $\mathrm{B}$ & \\
\hline d. & Tomato & $\mathrm{N}, \mathrm{P}, \mathrm{Ca}$, and $\mathrm{Na}$ & $\mathrm{Cr}$ and $\mathrm{Fe}$ & Vit.B1, B3, and C \\
\hline e. & Cauliflower & $\mathrm{Ca}, \mathrm{P}, \mathrm{Na}$, and $\mathrm{K}$ & $\mathrm{Cr}$ and $\mathrm{Fe}$ & Moisture and carbohydrates \\
\hline f. & Potato & $\mathrm{P}, \mathrm{Na}$, and $\mathrm{K}$ & $\mathrm{Ca}, \mathrm{Cr}$, and $\mathrm{Fe}$ & Vit. B3, C, moisture, and carbohydrates \\
\hline g. & Bottle gourd & $\mathrm{Ca}, \mathrm{P}$, and $\mathrm{K}$ & $\mathrm{Na}, \mathrm{Cr}$, and $\mathrm{Fe}$ & $\begin{array}{l}\text { Vit. C, moisture, proteins, and carbohy- } \\
\text { drates }\end{array}$ \\
\hline h. & Carrot & $\mathrm{Ca}, \mathrm{P}, \mathrm{Na}$, and $\mathrm{K}$ & $\mathrm{Cr}, \mathrm{Zn}, \mathrm{Mn}$, and $\mathrm{Fe}$ & Vit. B3, C, Moisture, and carbohydrates \\
\hline i. & Spinach & $\mathrm{Ca}, \mathrm{P}, \mathrm{Na}, \mathrm{Fe}$, and $\mathrm{K}$ & $\mathrm{Cr}$ & Vit. B1, B2, B3, C, moisture, and protein \\
\hline $\mathrm{j}$. & Sweet pepper (capsicum) & $\mathrm{Ca}, \mathrm{P}, \mathrm{Na}, \mathrm{Fe}$, and $\mathrm{K}$ & $\mathrm{Cr}$ & \\
\hline \multicolumn{5}{|c|}{ Fruit peels } \\
\hline a. & Mango & \multicolumn{3}{|c|}{ Polyphenol, dietary fibre, Vit. C, E, the rich source of pectins and flavonoids. } \\
\hline b. & Papaya & \multicolumn{3}{|c|}{$\mathrm{N}_{2}, \mathrm{Ca}, \mathrm{K}, \mathrm{Mg}, \mathrm{Cu}, \mathrm{Zn}$} \\
\hline c. & Watermelon & \multicolumn{3}{|c|}{$\mathrm{P}, \mathrm{Na}, \mathrm{Ca}, \mathrm{K}, \mathrm{Mg}, \mathrm{Fe}, \mathrm{Zn}, \mathrm{Mn}, \mathrm{Cu}$} \\
\hline d. & Banana & \multicolumn{3}{|c|}{ Glucose, fructose, starch, $\mathrm{Fe}, \mathrm{K}, \mathrm{Na}, \mathrm{Ca}$ and $\mathrm{Mn}$} \\
\hline e. & Tea & \multicolumn{3}{|c|}{ Carbohydrates, polyphenols, flavanoids, amino acids (L-theanine) } \\
\hline f. & Egg shells & \multicolumn{3}{|l|}{ Calcium carbonate } \\
\hline
\end{tabular}

organic manure within 15-20 days. The organic manure was collected from the two pits.

Three samples (control sample, kitchen waste, and kitchen waste plus poultry faeces) were heated in an oven at $50{ }^{\circ} \mathrm{C}$ to remove any moisture. The dried samples were ground into uniform powder. The samples were coded as S2 for control soil, SK2 for kitchen waste, and SKC2 for kitchen waste with poultry faeces samples, respectively. Next, the samples were carbonized at $800{ }^{\circ} \mathrm{C}$ in an inert gas (Ar) atmosphere. The carbonization was carried out for $4 \mathrm{~h}$. The activated samples were then washed with $1 \times 10^{3} \mathrm{M} \mathrm{HCl}$ and $2.74 \times 10^{-3} \mathrm{M}$ EDTA. The washing of activated samples is necessary for removing the traces of any heavy metals. It involved the treatment of $6 \mathrm{~g}$ sample $(<2.0 \mathrm{~mm})$ with $30 \mathrm{ml}$ volume of extracting solutions. The mixture was taken into centrifuge tubes and each sample was centrifuged for $60 \mathrm{~min}$ at about $1200 \mathrm{rpm}$ [28]. The supernatant solutions were then filtered and the solid residue was collected into the Petri dishes and dried in an oven at $50{ }^{\circ} \mathrm{C}$ overnight.

\section{Instrumentation}

A JEOL JED-2300F Field Emission Scanning Electron Microscope (FESEM) equipped with Energy Dispersive Spectrometer (EDS) having a voltage capacity between 0.5 and $30 \mathrm{kV}$ was used to evaluate the surface morphology of the processed samples.
$\mathrm{N}_{2}$ adsorption and desorption isotherms were measured using NOVA 2000e (Quantachrome) surface area and pore size analyzer to obtain the Brunauer-Emmett-Teller (BET) surface area and pore size distributions.

For analyzing the structural morphology of the samples, a Panalytical's X'Pert Pro X-ray Diffraction was used. The instrument consists of vertical theta-theta goniometer having a range of $0^{\circ}-160^{\circ}$ 2-theta. The radiation used is $\mathrm{Cu}$ $\mathrm{K}$-alpha-1, whereas nickel metal is used as a beta filter. For sample preparation, $2 \mathrm{~g}$ fine powder sample or sample on glass slide of size $3.5 \mathrm{~cm} \times 2.5 \mathrm{~cm}$ and thickness $0.2 \mathrm{~cm}$ with uniform sample layer on one side is required for obtaining the diffractogram.

To examine the functional groups and assess the chemistry of the samples, FTIR spectra were recorded on a Perkin Elmer-Spectrum RX-FTIR in the scan range of $400-4000 \mathrm{~cm}^{-1}$.

The electrochemical measurements were performed using Bio-Logic SP-150, a computer-controlled potentiostat with a typical three-electrode cell. A platinum wire was used as counter electrode and $\mathrm{Ag} / \mathrm{AgCl} / 3.0 \mathrm{M} \mathrm{NaCl}$ as reference electrode. All the experiments were conducted at room temperature. The electrodes for electrochemical measurements in the three-electrode system were prepared by introducing a predetermined amount ( $2 \mathrm{mg}$ ) of various samples in loading $10 \mu \mathrm{L}$ of processed kitchen waste and ionomer mixed solution on to the surface glassy carbon electrode (GCE). 
LSV curves of ORR on GCE in $\mathrm{O}_{2-}$ saturated $0.1 \mathrm{M} \mathrm{KOH}$ solutions were recorded at a scan rate of $10 \mathrm{mVs}^{-1}$. Cyclic voltammetry $(\mathrm{CV})$ was performed in $\mathrm{O}_{2}$-saturated $0.1 \mathrm{M}$ $\mathrm{KOH}$ solutions. The electrode area was $0.07 \mathrm{~cm}^{2}$. CV measurements were performed at scan rates of $50 \mathrm{mVs}^{-1}$ between the potentials of $-0.8 \sim 0 \mathrm{~V}$ vs SHE. All potentials in the text are represented based on $\mathrm{Ag} / \mathrm{AgCl} / \mathrm{sat}{ }^{\prime} \mathrm{KCl}$.

\section{Results and Discussion}

Figure 1a-c shows FESEM images of the samples S2, SK2, and $\mathrm{SKC} 2$, respectively. The development of porosity has been observed in all of them, and an inset of the sample S2 in Fig. 1a shows a closer view of the porous arrangements in it.

The porous developments in all the samples very much owe to the kitchen-waste decomposing medium too, which is the ground here. The ground acts as the natural template for the porous arrangement generation in all the samples. BET surface area analysis reveals the porosity and pore volumes of all the samples. The pore volumes were found to be $0.10,0.06$, and $0.04 \mathrm{~cm}^{3} \mathrm{~g}^{-1}$ for S2, SK2, and SKC2 samples, respectively. The average pore diameters for the same order of samples were noted to be 5.86, 8.08, and $10.29 \mathrm{~nm}$, highlighting their mesoporous nature. BET surface area was $3.477 \mathrm{~m}^{2} \mathrm{~g}^{-1}$ for $\mathrm{S} 2,1.776 \mathrm{~m}^{2} \mathrm{~g}^{-1}$ for SK2, and $0.8267 \mathrm{~m}^{2} \mathrm{~g}^{-1}$ for the sample SKC2. It shows that the processed samples (SK2 and SKC2) exhibited lower surface area and pore volumes, but increased pore sizes as compared to the control sample (S2). As shown in $\mathrm{N}_{2}$-sorption isotherms in Fig. 2, all the samples exhibited type IV isotherm curves which signifies the presence of mesopores in them [29]. This highlights their suitability for the electrocatalytic applications, as mesoporous size distributions $(2-50 \mathrm{~nm})$ are highly desirable for the faster diffusion of larger molecules into the internal porous surface of carbons. Hierarchical porous carbon structures with multimodal (meso- and micro-porous) pore size distributions are advantageous for the ORR in an FC, microporosity provides numerous accessible active sites,
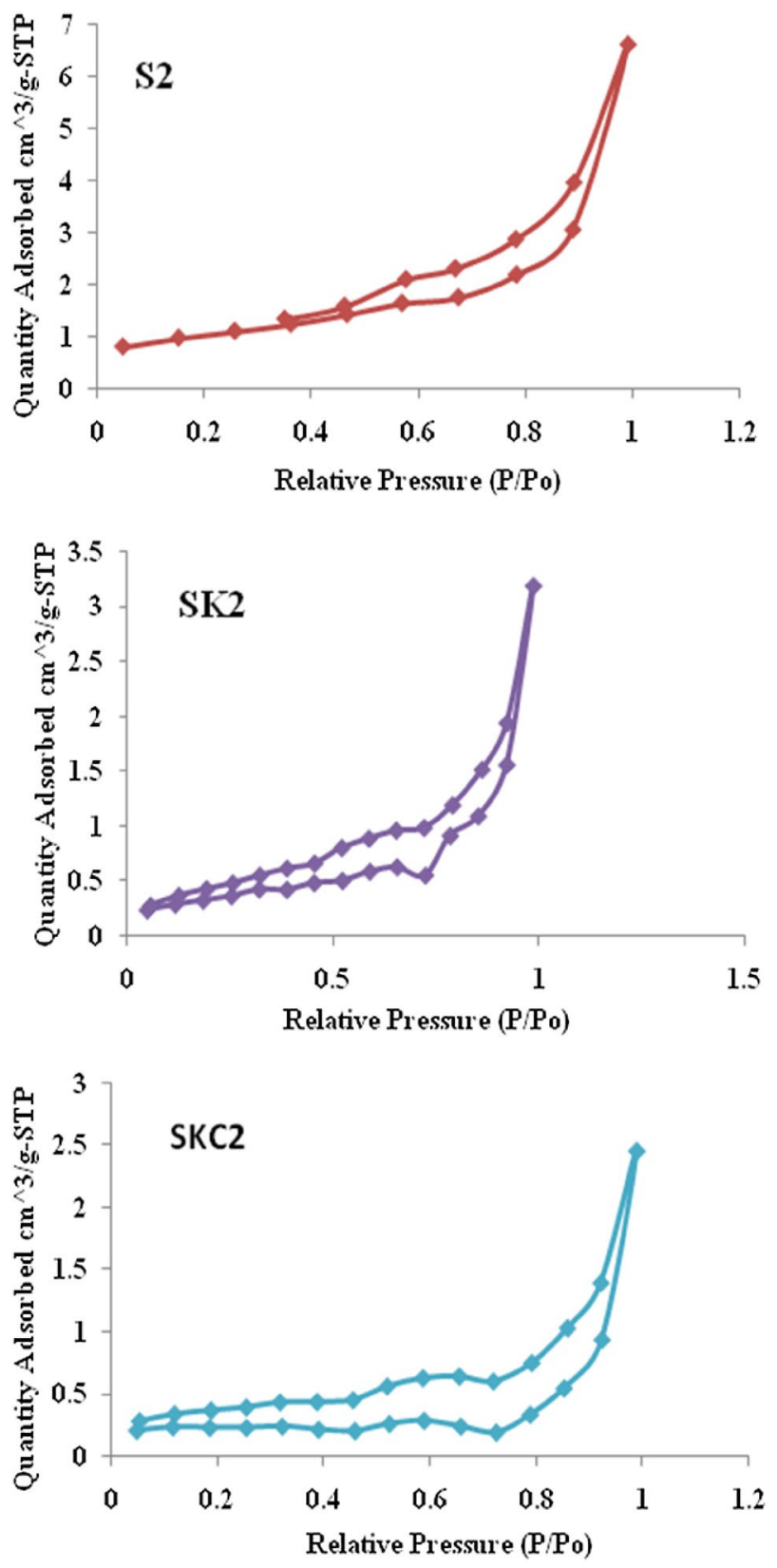

Fig. $2 \mathrm{~N}_{2}$ adsorption-desorption isotherms for the samples $\mathrm{S} 2$, SK2, and $\mathrm{SKC} 2$
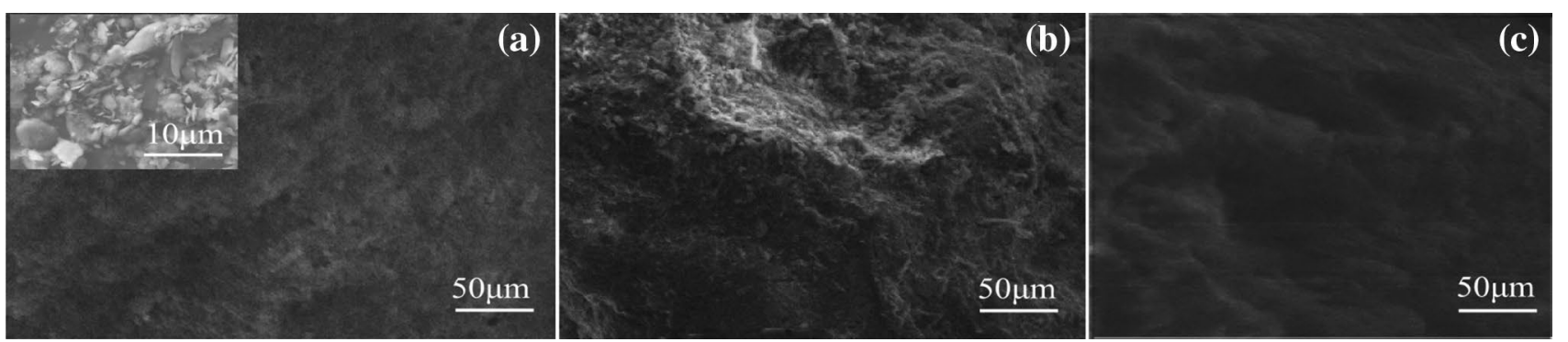

Fig. 1 a-c FESEM images for the samples S2, SK2, and SKC2, respectively. An inset in a shows a closer view of the mesoporous arrangements in $\mathrm{S} 2$ 
and mesoporosity facilitates efficient mass transport in the catalyst layers [30].

The presence of various heteroatoms in the porous arrangement of all the samples was further confirmed by EDS analysis. The spectra are shown in Fig. 3, and the sample composition analysis is given in Table 2. It has been established that all of them contain significant portions of various dopants, most importantly $\mathrm{N}$ and $\mathrm{O}$, which have been considered to be vital for an improved catalytic performance of the electrocatalysts to speed up the kinetics of ORR in an FC [31]. A comparison of the amount of $\mathrm{N}$ content present in all the samples shows that SKC2 sample contains the maximum doping content, and the amount is significantly higher than the samples S2 and SK2. In addition, the doped N content varies slightly in the other two samples (S2 and SK2). It shows that the treatment of the organic manure with the poultry faeces has resulted in an increased $\mathrm{N}$ content in the sample SKC2. It is important to say here that the doped $\mathrm{N}$ content in all the samples is either comparable or higher than previously reported biomass-derived PCM-based electrocatalysts [32-39]. It again signifies the utilization of kitchen waste-based organic manure for the electrocatalytic applications in futuristic clean energy devices. However, a detailed study of the doped $\mathrm{N}$ content and the N-bonding configurations is required further which reveals the exact role of the heteroatoms content for an improved electrocatalytic performance and the operational stability of an electrocatalyst.

Further analysis of values in Table 2 shows the presence of higher $\mathrm{O}, \mathrm{Mg}, \mathrm{Al}$, and $\mathrm{K}$ contents in the sample SK2 as compared to other two samples (S2 and SKC2). Maximum $\mathrm{C}$ content is present in the sample $\mathrm{S} 2$. The presence of $\mathrm{Si}$ and $\mathrm{Ti}$ contents is obvious, as the kitchen waste was decomposed into soil. Fe has been observed to be present in all the samples. It is to be noted here that the amount of doped Fe content is not much higher in the samples SK2 and SKC2 as compared to the sample S2. It shows that the washing treatments (in sect. "Experimental section") given to the samples for the heavy metals removal are successful. However, a complete removal of the Fe content is vital to achieve metal-free electrocatalysis of an electrocatalyst, as Fe plays its role in the electrocatalytic activity of an electrocatalyst [40].

Bulk composition analysis of the three samples was also performed to check the \% of organic matter, $\mathrm{N}$ and the $\mathrm{P}$ contents in three samples. S2 contains organic matter $2.14 \%$, $\mathrm{N}$ content $120.7 \mathrm{~kg} / \mathrm{ha}$, and $\mathrm{P}$ content $0.67 \mathrm{~kg} / \mathrm{ha}$. SK 2 contains organic matter $0.42 \%, \mathrm{~N}$ content $246.20 \mathrm{~kg} / \mathrm{ha}$, and $\mathrm{P}$ content $1.61 \mathrm{~kg} / \mathrm{ha}$. SKC2 contains organic matter $1.46 \%, \mathrm{~N}$ content $324.60 \mathrm{~kg} / \mathrm{ha}$, and $\mathrm{P}$ content $1.79 \mathrm{~kg} / \mathrm{ha}$. It has been observed that the organic matter content is the maximum in the sample S2, preceding it are the samples SKC2 and SK2. The doped $\mathrm{N}$ content is the maximum for the sample SKC2 and minimum for the sample S2. These results are consistent with the EDS analysis. In addition, it has been observed that the doped $\mathrm{P}$ content is the maximum for the sample SKC2 and minimum for the sample S2. However, the values are very less as compared to the doped $\mathrm{N}$ content. Both these dopants are important to achieve a higher electrocatalytic performance of an electrocatalyst [41].

The amount of disorder introduced by the presence of different heteroatoms in the samples SK2 and SKC2 was further studied by XRD spectra. For comparison, XRD of
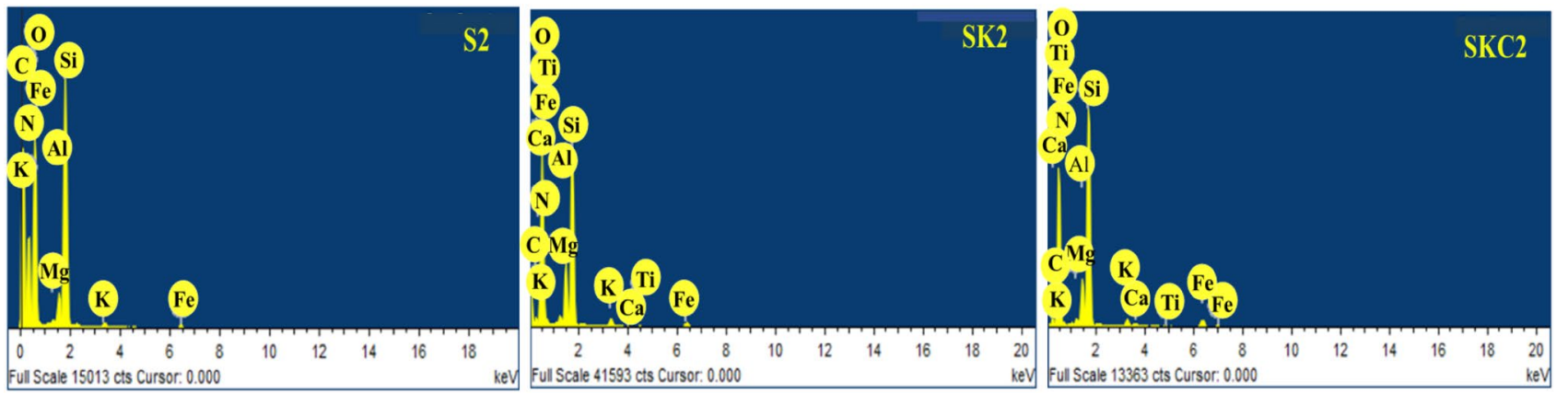

Fig. 3 EDS spectra of the samples S2, SK2, and SKC2

Table 2 Elemental compositions (at. \%) of the samples S2, SK2, and SKC2, respectively

\begin{tabular}{|c|c|c|c|c|c|c|c|c|c|c|}
\hline \multirow[t]{2}{*}{ Sample name } & \multicolumn{10}{|c|}{ Elements (at. \%) } \\
\hline & $\mathrm{C}$ & $\mathrm{N}$ & $\mathrm{O}$ & $\mathrm{Mg}$ & $\mathrm{Al}$ & $\mathrm{Si}$ & $\mathrm{K}$ & $\mathrm{Fe}$ & $\mathrm{Ca}$ & $\mathrm{Ti}$ \\
\hline $\mathrm{S} 2$ & 45.8 & 6.3 & 42.7 & 0.1 & 0.6 & 4.4 & 0.1 & 0.1 & 0 & 0 \\
\hline SK2 & 18.2 & 6.7 & 62.9 & 0.5 & 2.9 & 7.9 & 0.3 & 0.4 & 0.1 & 0.04 \\
\hline $\mathrm{SKC} 2$ & 18.9 & 9.2 & 59.3 & 0.3 & 1.9 & 9.2 & 0.3 & 0.6 & 0.1 & 0.06 \\
\hline
\end{tabular}



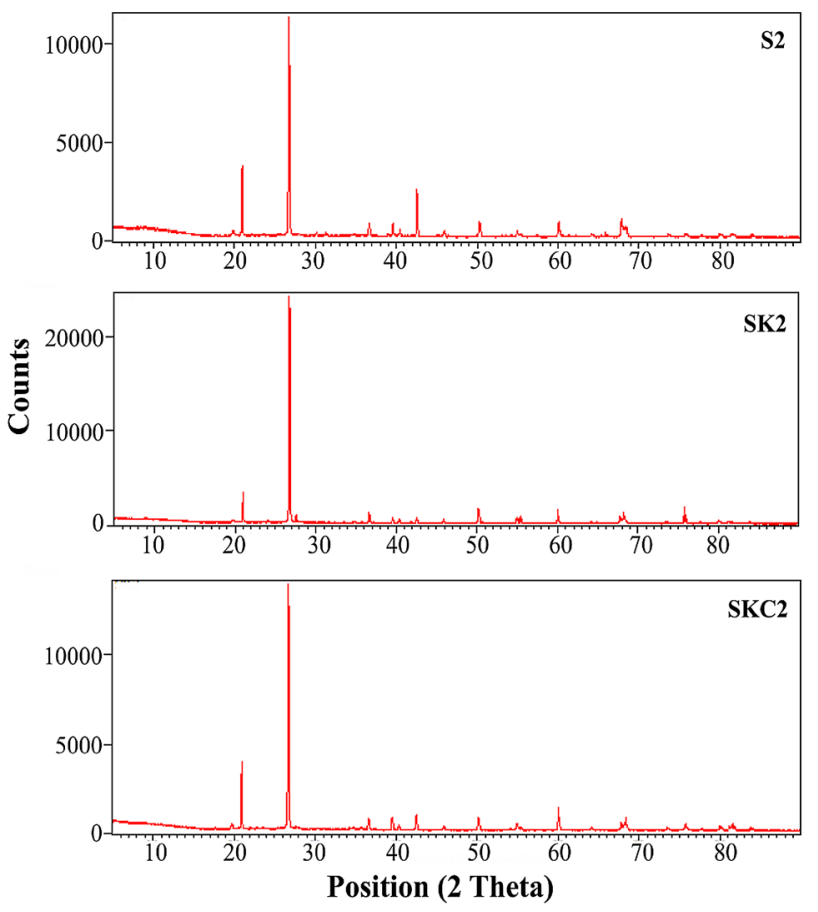

Fig. 4 XRD patterns for the samples S2, SK2, and SKC2. A negative (left) shift in the characteristic peaks is clearly visible for the samples SK2 and SKC2, as compared to S2

the sample S2 was also performed. In Fig. 4, all the spectra show the presence of two peaks located at $26.72^{\circ}: 42.76^{\circ}$, $26.66^{\circ}: 42.53^{\circ}$, and $26.70^{\circ}: 42.32^{\circ}$ for the samples S2, SK2, and SKC2, respectively. The peaks correspond to the (002) and (100) lattice planes of a typical turbostratic $C$ structure [42]. No characteristic signals for the salts or impurities were observed, however. The lattice spacing is $0.333 \mathrm{~nm}$ for the sample S2, $0.334 \mathrm{~nm}$ for the sample SK2, and $0.335 \mathrm{~nm}$ for the sample SKC2. This shows the presence of graphitic C. It has been reported previously that the $\mathrm{C}$ graphitization of a catalyst leads to its enhanced conductivity, so it again confirms the utilization of these samples for the electrocatalytic applications [43]. Bit higher values of lattice spacing in the kitchen waste-based organic manure samples (SK2 and SKC2) confirm the presence of more heteroatoms doped in it, and hence a higher disorder in these. A negative shift in the peak values also confirms the doping of heteroatoms in the graphitic carbons of samples SK2 and SKC2 as compared to sample $\mathrm{S} 2$ and more disordered graphitic C structures in these. A left-shift in the peak values gives rise to increased d-spacing values and it has been indeed observed here [44]. FESEM images (Fig. 1b, c) also shows higher disorder as compared to control sample of Fig. 1a. A higher disorder is shown by the turbulent wave-like structure in these samples (SK2 and SKC2) and indicates morphology changes taking place in these samples. S2 sample has been observed to be more planar and exhibits better morphological ordering.

Next, FTIR spectroscopy study was performed to get an insight into the chemical bond formation or dissociation in the samples upon their high-temperature treatment. The spectra are shown in Fig. 5 for all the samples. An occurrence of sharp peaks at high temperature shows the formation of stable bonds at this range. A detailed analysis of the most prominent peaks is given in Table 3 [45]. It has been observed in FTIR spectra that all the samples exhibit similar characteristic peaks except the sample SKC2, which exhibits two more peaks at 2960 and $2840 \mathrm{~cm}^{-1}$. These peaks correspond to characteristic $\mathrm{C}-\mathrm{H}$ stretching and relate to the presence of more saturated carbons in it. The region above $3000 \mathrm{~cm}^{-1}$ corresponds to unsaturated carbons (alcohols, amines, amides, or carboxylic acid functional groups). The peak intensity at $3630.844 \mathrm{~cm}^{-1}$ is more for the samples S2 and SKC2 as compared to S2 indicating the presence of more unsaturated carbons in it. The peaks at 2238, 1524, 1275 , and $1044 \mathrm{~cm}^{-1}$ correspond to $\mathrm{C} \equiv \mathrm{N}$ stretching, $\mathrm{N}-\mathrm{O}$ nitro compounds, $\mathrm{C}-\mathrm{N}$ aromatic amines, and $\mathrm{C}-\mathrm{N}$ stretch, respectively. These peaks are more pronounced for the sample SKC2 as compared to S2 or SK2, as it contains higher $\mathrm{N}$ content (as discussed above). The peaks at 472.790 and
Fig. 5 FTIR spectra of the samples S2, SK2, and SKC2

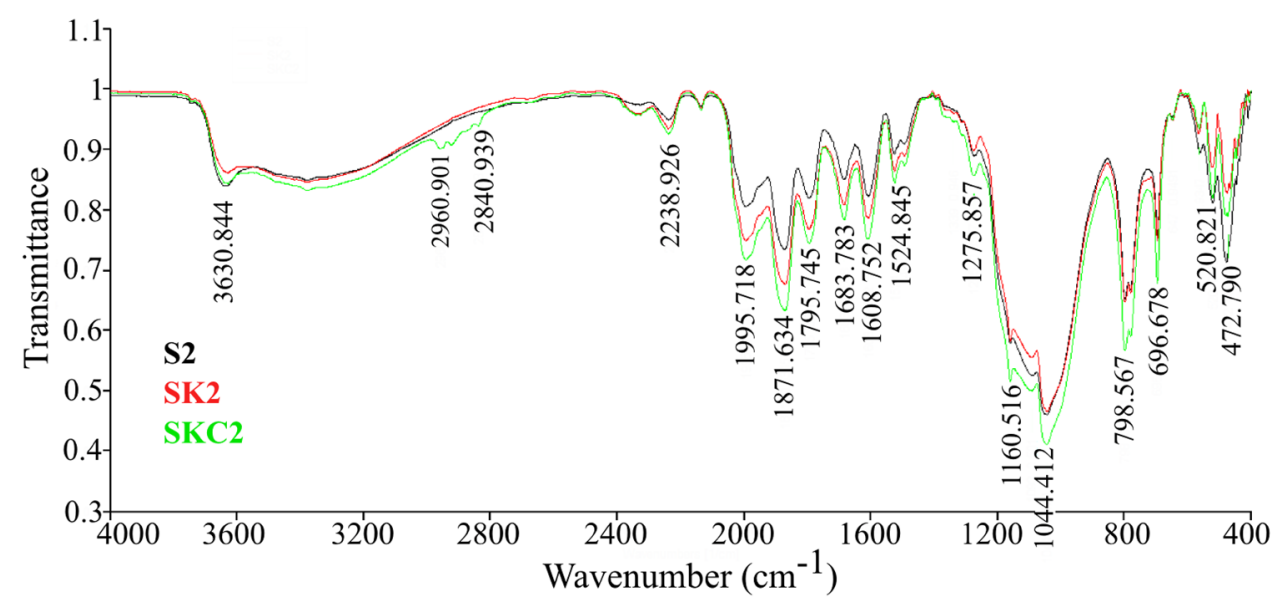


Table 3 Peak assignments in FTIR spectroscopy of samples S2, SK2, and $\mathrm{SKC} 2$

\begin{tabular}{|c|c|c|}
\hline S. no. & Assignment & $\begin{array}{l}\text { Peak } \\
\text { frequency } \\
\left(\mathrm{cm}^{-1}\right)\end{array}$ \\
\hline 1. & $\mathrm{O}-\mathrm{H}$ stretching & 3630.844 \\
\hline 2. & $\mathrm{C}-\mathrm{H}$ stretching & 2960.901 \\
\hline 3. & $\mathrm{C}-\mathrm{H}$ stretching & 2840.939 \\
\hline 4. & $\mathrm{C} \equiv \mathrm{N}$ stretching & 2238.926 \\
\hline 5. & $\mathrm{C}=\mathrm{C}=\mathrm{C}$ stretching & 1995.718 \\
\hline 6. & $\mathrm{C} \equiv \mathrm{C}$ stretching & 1871.634 \\
\hline 7. & $\mathrm{C}=\mathrm{C}$ stretching & 1608.752 \\
\hline 8. & $\mathrm{C}-\mathrm{H}$ bending & 798.567 \\
\hline 9. & $\mathrm{C}-\mathrm{H}$ bending & 696.678 \\
\hline 10. & $\begin{array}{l}\text { Alkenyl C-H stretch } \\
\text { alkenyl } \mathrm{C}=\mathrm{C} \text { stretch }\end{array}$ & 1683.783 \\
\hline 11. & $\mathrm{C}=\mathrm{O}$ carbonyls & 1795.745 \\
\hline 12. & $\mathrm{~N}-\mathrm{O}$ nitro compounds & 1524.845 \\
\hline 13. & $\mathrm{C}-\mathrm{N}$ aromatic amines & 1275.857 \\
\hline 14. & $\mathrm{C}-\mathrm{H}$ alkyl halides & 1160.516 \\
\hline 15. & $\mathrm{C}-\mathrm{N}$ stretch & 1044.412 \\
\hline 16. & $\begin{array}{l}\text { Alkyl halides } \\
\text { (C-Br, C-Cl, C-F) }\end{array}$ & 520.821 \\
\hline 17. & $\begin{array}{l}\text { Alkyl halides } \\
(\mathrm{C}-\mathrm{Br}, \mathrm{C}-\mathrm{Cl}, \mathrm{C}-\mathrm{F})\end{array}$ & 472.790 \\
\hline
\end{tabular}
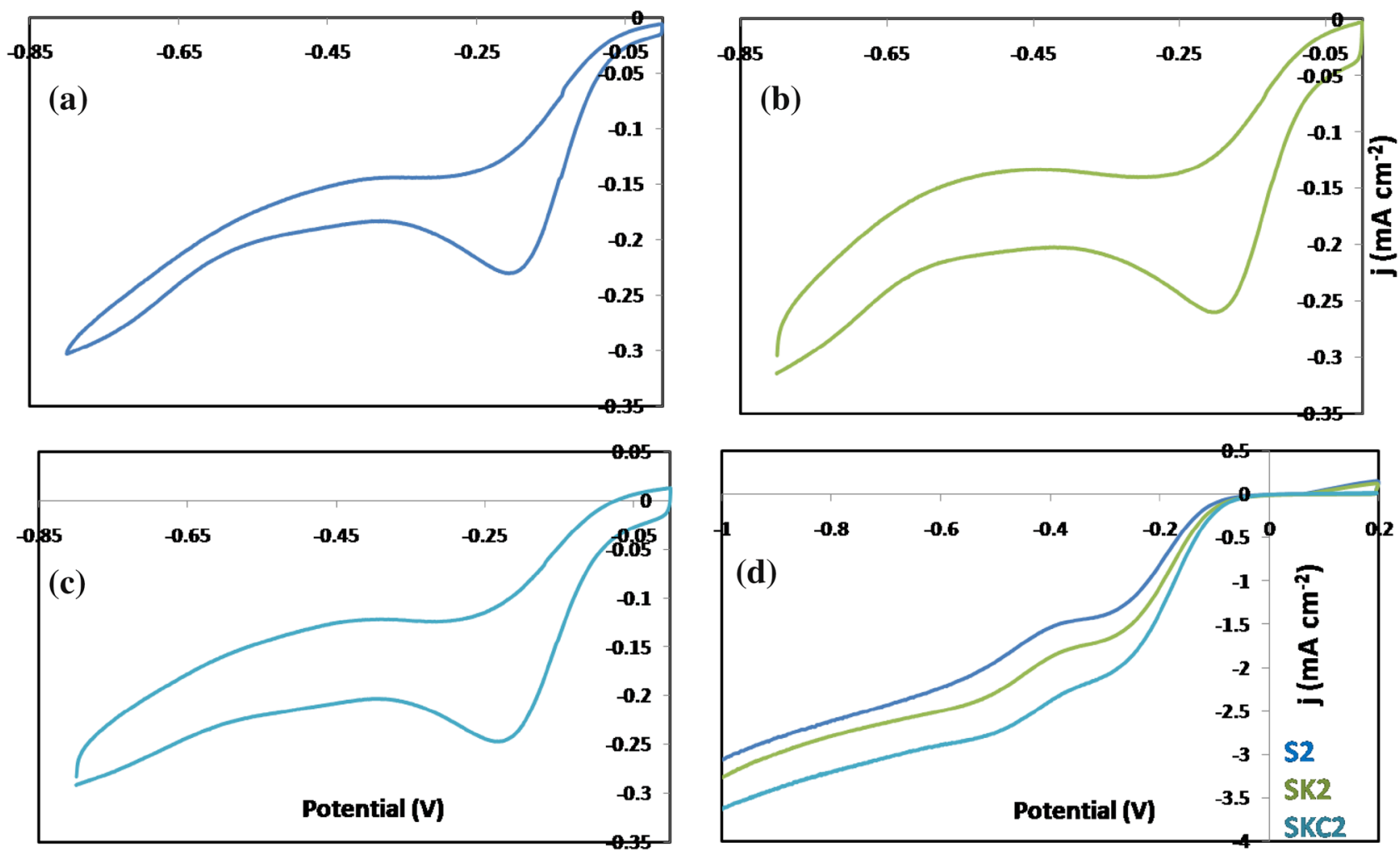

$520.821 \mathrm{~cm}^{-1}$ indicate the presence of more alkyl halides in the control sample (S2) as compared to SK2 or SKC2.

The CV study was performed to study the electrocatalytic performance of the samples. The analysis was performed in $0.1 \mathrm{M} \mathrm{KOH}$ solution saturated with $\mathrm{O}_{2}$ at a scan rate of $50 \mathrm{mVs}^{-1}$. The plots for all the samples are shown in Fig. 6a-c, respectively. The cyclic voltammograms of all the samples clearly show the characteristic two-step electron reduction process, with peak potential occurring at $-0.04 \mathrm{~V}$ for the sample S2 (Fig. 6a). Similarly, the peak potential for the samples SK2 and SKC2 is at -0.012 and $-0.006 \mathrm{~V}$, respectively (Fig. 6b, c). A positive shift in the reduction potential of $-0.034 \mathrm{~V}$ has been observed in the oxygen reduction peak potential of SKC2 as compared to $\mathrm{S} 2$ and $-0.028 \mathrm{~V}$ as compared to SK2. It clearly shows that SKC2 is more active as compared to the other two electrocatalysts. Therefore, it is evident from the CV that the sample SKC2 with the highest percentage of $\mathrm{N}$ in it shows the best reduction potential. It can be concluded here that the additional treatment with poultry faeces has significantly affected the electron reduction process by providing more oxygen containing functional groups on the surface of the activated carbons and the increased $\mathrm{N}$-doping content.

The preliminary electrochemical behaviour of the samples S2, SK2, and SKC2 has also been investigated using

Fig. 6 a-c Cyclic voltammograms of the samples S2, SK2, and SKC2. d LSV plots for ORR in an $\mathrm{O}_{2}$ saturated $0.1 \mathrm{M}$ KOH solution at a scan rate of $10 \mathrm{mVs}^{-1}$. The rotation rate is $1600 \mathrm{rpm}$ 
glassy carbon RDE. In general, the values of onset potential and peak current give a qualitative estimation of the electrocatalytic activity of an electrocatalyst. Lower onset potential and higher peak current indicate higher electrocatalytic activity of an electrocatalyst towards ORR. The ORR performance of all the samples (S2, SK2, and SKC2) has been investigated by LSV measurements on an RDE. The measurements were made with $\mathrm{O}_{2}$-saturated $0.1 \mathrm{M} \mathrm{KOH}$ solution at a scan rate of $10 \mathrm{mVs}^{-1}$ and a rotation rate of $1600 \mathrm{rpm}$. The results for all the samples are shown in Fig. 6d.

The presence of $\mathrm{N}$ in the porous carbonaceous structure of processed kitchen waste leads to polarized $\mathrm{C}-\mathrm{N}$ bonds. The charge redistribution and a higher electronegativity of $\mathrm{N}$ play an important part in enhancing the oxygen adsorption and the charge transfer, and in turn the electrocatalytic activity of an electrocatalyst. A positive charge on the $\mathrm{C}$ atoms neighbouring $\mathrm{N}$ facilitates the oxygen adsorption which is the first step towards an efficient ORR. The onset potential of ORR at $-0.025 \mathrm{mAcm}^{-2}$ for the electrode S2 starts at $-0.125 \mathrm{~V}$ followed by an increase in the current density (as shown in Fig. 6d). For the electrode SK2 and SKC2, ORR onset potential shifts positively to -0.106 and $-0.104 \mathrm{~V}$, respectively, followed by an increase in the current density and limiting diffusion current. Interestingly, the onset potential of ORR for the electrode SKC2 is comparable to the commercial Pt/C-based electrocatalyst [46]. The chicken manure-based processed kitchen waste sample (SKC2) exhibits current density and the ORR onset potential comparable to $\mathrm{Pt} / \mathrm{C}$-based electrocatalyst as compared to the other two samples (S2 and SK2). It points towards the suitability of these materials as ORR electrocatalysts for the FC. However, further more electrochemical studies should be undertaken on these materials to get an in depth knowledge and improvement of their performance.

Above results give a strong hint towards the successful utilization of the processed kitchen waste for the synthesis of mesoporous carbons and further their utilization for electrocatalytic applications. The presence of mesopores and a higher doped $\mathrm{N}$ content are altogether important for catalysis-based applications. N-doping in graphitic carbons is special as it is more electronegative element than $\mathrm{C}$; hence, $\mathrm{C}-\mathrm{N}$ bonds are polarized. $\mathrm{N}$ in its vicinity makes the $\mathrm{C}$ atom electron deficient and promotes the $\mathrm{O}_{2}$ adsorption on a graphitic $\mathrm{C}$ structure $[47,48]$. The charge delocalization upon the introduction of $\mathrm{N}$ dopants into $\mathrm{C}$ structure dissociates the $\mathrm{O}-\mathrm{O}$ bonds and facilitates the ORR occurring at the cathode of an FC. Therefore, a significant amount of $\mathrm{N}$ dopants present in the sample SKC2 is advantageous from the applications point of view.

The versatility of the results for the control sample and the kitchen waste-based samples is attributed to their treatments and the additives used. Although they were treated at the same temperature $\left(900^{\circ} \mathrm{C}\right)$, different biomass sources were used in all. In SK2, kitchen waste (vegetable and fruit peels, egg shells, and tea) was used, SKC2 consisted of kitchen waste mixed with poultry faeces, and no such biomass was used in the control sample S2. The addition of poultry faeces has been observed to lead to a higher doped $\mathrm{N}$ content and increased pore sizes in the sample SKC2. Any biomass source consists of three basic structural components, lignin, cellulose, and hemicelluloses. It is a complex mixture of inorganic and organic matter, and also contains varied contents of liquid and solid phases. All these phases are a result of their origin, time, and formation process. Therefore, each biomass source has different characteristic behaviours under a given heat treatment and may result in the varied characteristics of the synthesized porous carbons. It has been said in the previous studies that the composition of any biomass is more important than the interactions between its individual components, and it leads to its characteristic behaviour under a given physical, thermal, or chemical treatment [49].

\section{Conclusion}

We have suggested an effortless and cost-effective route to synthesize mesoporous carbons using residual biomass in this work. Kitchen waste was collected and treated to reduce it into organic manure, which was further given hightemperature treatments to get porous carbons valuable for energy applications. To enrich the organic manure with $\mathrm{N}$, poultry faeces were also added additionally to kitchen waste, and it has been observed to give a higher doped $\mathrm{N}$ content and increased pore sizes of the synthesized mesoporous carbons. The presence of graphitic carbons and variety of doped heteroatoms in the porous carbons make them suitable for a variety of applications and in particular for electrocatalytic applications. A positive shift in the oxygen reduction onset potential of the kitchen waste and chicken manure-based electrocatalyst as compared to other samples, and its comparable electrocatalytic performance to $\mathrm{Pt} / \mathrm{C}$ shows its suitability as ORR electrocatalyst in an FC. This study not only stimulates the development of sustainable and economical electrocatalysts for the FC, but also enlightened a new way to reuse and minimize the filthy waste. More optimization and electrochemical studies on this system will be carried on further, to get details of the exact $\mathrm{N}$-bonding configurations (pyridinic-N, pyrrolic-N, graphitic-N, and pyridinic-oxide$\mathrm{N}$ ) in the porous carbons, the role of temperature, surface area, and their role in the increased electrocatalytic activity of an electrocatalyst.

Acknowledgements P. K. thanks SERB (DST), New Delhi for the award of National Post-doc Fellowship (PDF/2015/000817). G.V. acknowledges the contribution of SAP (UGC, New Delhi), PURSE (DST, New Delhi), and TEQIP-II grants (Dr. SSB UICET). Authors 
acknowledge the help extended by Prof. J.D. Sharma and Mr. Sushil Kumar (PEC University of Technology, Chandigarh) during experimental work. The help extended by Prof. S. S. Sekhon and Dr. J.-S. Park, for providing us the electrochemical studies, is also duly acknowledged.

Open Access This article is distributed under the terms of the Creative Commons Attribution 4.0 International License (http://creativeco mmons.org/licenses/by/4.0/), which permits unrestricted use, distribution, and reproduction in any medium, provided you give appropriate credit to the original author(s) and the source, provide a link to the Creative Commons license, and indicate if changes were made.

\section{References}

1. Tuller, H.L.: Solar to fuels conversion technologies: a perspective. Mater. Renew. Sustain. Energy 6(3), 1-16 (2017)

2. Zuo, S., Xiao, Y., Liu, Y., Qiu, H., Guan, Q., Zheng, M.: Green and low-cost materials as carbon source for the synthesis of hierarchical porous carbons. J. Mater. Sci. 45, 4439-4443 (2010)

3. Anca-Couce, A.: Reaction mechanisms and multi-scale modelling of lignocellulosic biomass pyrolysis. Prog. Energy Combust. Sci. 53, 41-79 (2016)

4. Collard, F.X., Blin, J.: A review on pyrolysis of biomass constituents: mechanisms and composition of the products obtained from the conversion of cellulose, hemicelluloses and lignin. Renew. Sust. Energ. Rev. 38, 594-608 (2014)

5. Vassilev, S.V., Baxter, D., Andersen, L.K., Vassileva, C.G.: An overview of the chemical composition of biomass. Fuel 89, 913933 (2010)

6. Vassilev, S.V., Baxter, D., Andersen, L.K., Vassileva, C.G., Morgan, T.J.: An overview of the organic and inorganic phase composition of biomass. Fuel 94, 1-33 (2012)

7. Lebedeva, M.V., Yeletsky, P.M., Ayupov, A.B., Kuznetsov, A.N., Yakovlev, V.A., Parmon, V.N.: Micro-mesoporous carbons from rice husk as active materials for supercapacitors. Mater. Renew. Sustain. Energy 4(20), 1-9 (2015)

8. Tilahun, M., Sahu, O., Kotha, M., Sahu, H.: Cogeneration of renewable energy from biomass (utilization of municipal solid waste as electricity production: gasification method). Mater. Renew. Sustain. Energy 4(4), 1-8 (2015)

9. Yang, Y., Chiang, K., Burke, N.: Porous carbon-supported catalysts for energy and environmental applications: a short review. Catal. Today 178, 197-205 (2015)

10. Debe, M.K.: Electrocatalyst approaches and challenges for automotive fuel cells. Nature 486, 43-51 (2012)

11. Zhou, M., Wang, H.L., Guo, S.: Towards high-efficiency nanoelectrocatalysts for oxygen reduction through engineering advanced carbon nanomaterials. Chem. Soc. Rev. 45, 1273-1307 (2016)

12. Stacy, J., Regmi, Y.N., Leonard, B., Fan, M.: The recent progress and future of oxygen reduction reaction catalysis: a review. Renew. Sustain. Energy Rev. 69, 401-414 (2017)

13. Sun, Y., Duan, Y., Hao, L., Xing, Z., Dai, Y., Li, R., Zou, J.: Cornstalk-derived nitrogen-doped partly graphitized carbon as efficient metal-free catalyst for oxygen reduction reaction in microbial fuel cells. ACS Appl. Mater. Interfaces. 8, 25923-25932 (2016)

14. Yuan, W., Feng, Y., Xie, A., Zhang, X., Huang, F., Li, S., Zhang, X., Shen, Y.: Nitrogen-doped nanoporous carbon derived from waste pomelo peel as a metal-free electrocatalyst for the oxygen reduction reaction. Nanoscale 8, 8704-8711 (2016)

15. Gao, S., Li, X., Li, L., Wei, X.: A versatile biomass derived carbon material for oxygen reduction reaction, supercapacitors and oil/ water separation. Nano Energy 33, 334-342 (2017)
16. Zhang, L.Y., Zhou, Z., Liu, Z., Li, C.M.: An efficient electrocatalyst derived from bamboo leaves for the oxygen reduction reaction. Chem. Electro. Chem. 3, 1466-1470 (2016)

17. Guo, C., Hu, R., Liao, W., Li, Z., Sun, L., Shi, D., Li, Y., Chen, C.: Protein-enriched fish "biowaste" converted to three-dimensional porous carbon nano-network for advanced oxygen reduction electrocatalysis. Electrochim. Acta 236, 228-238 (2017)

18. Unni, S.M., George, L., Bhange, S.N., Devi, R.N., Kurungot, S.: Valorization of coffee bean waste: a coffee bean waste derived multifunctional catalyst for photocatalytic hydrogen production and electrocatalytic oxygen reduction reactions. RSC Adv. 6, 82103-82111 (2016)

19. Yuan, W., Chen, P., Xie, A., Li, S., Huang, F., Shen, Y.: Napkin paper derived nitrogen-doped carbon sheets: a high-performance electrocatalyst for oxygen reduction reaction. J. Electrochem. Soc. 163, H1204-H1209 (2016)

20. Rana, M., Subramani, K., Sathish, M., Gautam, U.K.: Soya derived heteroatom doped carbon as a promising platform for oxygen reduction, supercapacitor and $\mathrm{CO}_{2}$ capture. Carbon $\mathbf{1 1 4}$, 679-689 (2017)

21. Pathak, P.D., Mandavgane, S.A., Kulkarni, B.D.: Fruit peel waste: characterization and its potential uses. Curr. Sci. 113, 444-454 (2017)

22. Brunerova, A., Roubik, H., Brozek, M., Herak, D., Sleger, V., Mazancova, J.: Potential of tropical fruit waste biomass for production of bio-briquette fuel: using Indonesia as an example. Energies 10, 2119 (2017)

23. Deng, G.F., Shen, C., Xu, X.R., Kuang, R.D., Guo, Y.J., Zeng, L.S., Gao, L.L., Lin, X., Xie, J.F., Xia, E.Q., Li, S.: Potential of fruit wastes as natural resources of bioactive compounds. Int. J. Mol. Sci. 13, 8308-8323 (2012)

24. Li, Y., Zhang, J.J., Xu, D.P., Zhou, T., Zhou, Y., Li, S., Li, H.B.: Bioactivities and health benefits of wild fruits. Int. J. Mol. Sci. 17, 1258 (2016)

25. Khan, N., le Roes-Hill, M., Welz, P.J., Grandin, K.A., Kudanga, T., Ohlhoff, C., Van Dyk, J.S., Pletschke, B.I., Van Zyl, W.E.: Fruit waste streams in South Africa and their potential role in developing a bio-economy. S. Afr. J. Sci. 111, 1-11 (2015)

26. Divina, C.C.: Scraps no more: fruit wastes for benefits of plants and animals. Int. J. Agric. Technol. 12, 1537-1547 (2016)

27. Mazeika, R., Dambrauskas, T., Baltakys, K., Mikolajunas, M., Staugaitis, G., Virzonis, D., Baltrusaitis, J.: Molecular and morphological structure of poultry manure derived organo-mineral fertilizers (OMFs). ACS Sustain. Chem. Eng. 4, 4788-4796 (2016)

28. Tejowulan, R.S., Hendershot, W.H.: Removal of trace metals from contaminated soils using EDTA incorporating resin trapping techniques. Environ. Pollut. 103, 135-142 (1998)

29. Lee, J.S., Kim, S.I., Yoon, J.C., Jang, J.H.: Chemical vapor deposition of mesoporous graphene nanoballs for supercapacitor. ACS Nano 7, 6047-6055 (2013)

30. Corma, A.: From microporous to mesoporous molecular sieve materials and their use in catalysis. Chem. Rev. 97, 2373-2420 (1997)

31. Dai, L., Xue, Y., Qu, L., Choi, H.J., Baek, J.B.: Metal-free catalysts for oxygen reduction reaction. Chem. Rev. 115, 4823-4892 (2015)

32. Saravanan, K.R., Mullaivananathan, V., Kalaiselvi, N.: Dual hetero atom containing bio-carbon: multifunctional electrode material for high performance sodium-ion batteries and oxygen reduction reaction. Electrochim. Acta 176, 670-678 (2015)

33. Chaudhari, N.K., Song, M.Y., Yu, J.S.: Heteroatom-doped highly porous carbon from human urine. Sci. Rep. 4, 1-10 (2014)

34. Xiao, Z., Gao, X., Shi, M., Ren, G., Xiao, G., Zhu, Y., Jiang, L.: China rose-derived tri-heteroatom co-doped porous carbon as an

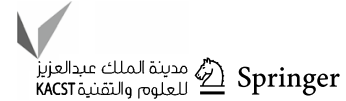


efficient electrocatalysts for oxygen reduction reaction. RSC Adv. 6, 86401-86409 (2016)

35. Ye, D., Wang, L., Zhang, R., Liu, B., Wang, Y., Kong, J.: Facile preparation of $\mathrm{N}$-doped mesocellular graphene foam from sludge flocs for highly efficient oxygen reduction reaction. J. Mater. Chem. A 3, 15171-15176 (2015)

36. Rana, M., Arora, G., Gautam, U.K.: N- and S-doped high surface area carbon derived from soya chunks as scalable and efficient electrocatalysts for oxygen reduction. Sci. Tech. Adv. Mater. 16(014803), 1-11 (2015)

37. Atchudan, R., Edison, T.N., Lee, Y.R.: Nitrogen-doped carbon dots originating from unripe peach for fluorescent bioimaging and electrocatalytic oxygen reduction reaction. J. Colloid Interface Sci. 482, 8-18 (2016)

38. Ma, X., Feng, C., Zhou, W., Yu, H.: Municipal sludge-derived carbon anode with nitrogen- and oxygen-containing functional groups for high-performance microbial fuel cells. J. Power Sources 307, 105-111 (2016)

39. Guo, C., Li, Z., Niu, L., Liao, W., Sun, L., Wen, B., Nie, Y., Cheng, J., Chen, C.: A nanopore-structured nitrogen-doped biocarbon electrocatalyst for oxygen reduction from two-step carbonization of lemna minor biomass. Nanoscale Res. Lett. 11, 1-6 (2016)

40. Lefevre, M., Proietti, E., Jaouen, F., Dodelet, J.P.: Iron-based catalysts with improved oxygen reduction activity in polymer electrolyte fuel cells. Science 324, 71-74 (2009)

41. Zheng, X., Cao, X., Wu, J., Tian, J., Jin, C., Yang, R.: Yolk-shell N/P/B ternary-doped biocarbon derived from yeast cells for enhanced oxygen reduction reaction. Carbon 107, 907-916 (2016)

42. Gao, S., Geng, K., Liu, H., Wei, X., Zhang, M., Wang, P., Wang, J.: Transforming organic-rich amaranthus waste into nitrogen-doped carbon with superior performance of the oxygen reduction reaction. Energy Environ. Sci. 8, 221-229 (2015)

43. Tang, J., Liu, J., Torad, N.L., Kimura, T., Yamauchi, Y.: Tailored design of functional nanoporous carbon materials toward fuel cell applications. Nano Today 9, 305-323 (2014)

44. Manoj, B., Kunjomana, A.G.: Study of stacking structure of amorphous carbon by X-ray diffraction technique. Int. J. Electrochem. Sci. 7, 3127-3134 (2012)

45. Stuart, B.: Infrared spectroscopy. Wiley, New York (2005)

46. Kaur, P., Shin, M.-S., Chae, S.-R., Kang, M.-S., Park, J.-S., Sekhon, S.S.: Functionalization of multiwall carbon nanotubes with nitrogen containing polyelectrolyte by a simple method. J. Phys. Chem. Solids 85, 155-159 (2015)

47. Gong, K., Du, F., Xia, Z., Durstock, M., Dai, L.: Nitrogen-doped carbon nanotube arrays with high electrocatalytic activity for oxygen reduction. Science 323, 760-764 (2009)

48. Cong, K., Radtke, M., Stumpf, S., Schroter, B., McMillian, D.G., Rettenmayr, M., Ignaszak, A.: Electrochemical stability of the polymer-derived nitrogen-doped carbon: an elusive goal? Mater. Renew. Sustain. Energy 4(5), 1-11 (2015)

49. Raveendran, K., Ganesh, A., Khilar, K.C.: Pyrolysis characteristics of biomass and biomass components. Fuel 75, 987-998 (1996)

Publisher's note Springer Nature remains neutral with regard to jurisdictional claims in published maps and institutional affiliations. 